\title{
FASHION INVOLVEMENT MEMPENGARUHI EMOSI POSITIF DAN HEDONISME TERHADAP IMPULSIVE BUYING DI GERAI ZARA BALI
}

\author{
Celina Andika Mulia ${ }^{1}$ \\ A.A. Gd. Agung Artha K. ${ }^{2}$ \\ ${ }^{1,2}$ Fakultas Ekonomi dan Bisnis Universitas Udayana, Bali, Indonesia \\ email: celinamulia@hotmail.com ${ }^{1}$
}

\begin{abstract}
ABSTRAK
Tujuan penelitian ini adalah untuk mengetahui bagaimana fashion involvement mempengaruhi emosi positif dan hedonisme terhadap impulsive buying konsumen produk fashion dalam konteks berbelanja. Dengan menggunakan model fashion involvement maka riset ini dikembangkan untuk menggali faktor-faktor yang berdampak pada impulsive buying oleh emosi positif dan hedonisme. Model tersebut diuji melalui kuisioner dari 85 responden yang pernah berbelanja di Zara Bali. Analisis yang digunakan adalah outter model dan inner model yang hasilnya didapat melalui program PLS. Hasil penelitian menemukan variabel fashion involvement, emosi positif dan hedonisme berpengaruh positif terhadap impulsive buying. Implikasi penelitian ini bawa fashion involvement memberi kontribusi pada emosi positif dan hedonisme terhadap impulsive buying. Implikasi teoritis penelitian ini diharapkan dapat dijadikan sebagai bahan studi lanjutan yang relevan dan menambah referensi terhadap variabel yang diteliti. Implikasi praktis yang diperoleh bahwa hasil penelitian ini diharapkan dapat menjadi pertimbangan dalam menetapkan strategi pemasaran perusahaan
\end{abstract}

Kata kunci: fashion involvement; emosi positif; hedonisme; impulsive buying.

\begin{abstract}
The purpose of this study is to find out how fashion involvement affects positive emotions and hedonism to impulsive buying consumer fashion products in the context of shopping. By using a fashion involvement model, this research was developed to explore the factors that have an impact on impulsive buying by positive emotions and hedonism. The model was tested through questionnaires from 85 respondents who had been shopping at Zara Bali. The analysis used is outter model and inner model which result obtained through PLS program. The results of the study found that fashion involvement, positive emotions and hedonism have a positive effect on impulsive buying. The implications of this study bring fashion involvement to contribute to positive emotions and hedonism to impulsive buying. The theoretical implications of this study are expected to serve as relevant study materials and add a reference to the variables studied. The practical implications obtained that the results of this study is expected to be a consideration in determining the company's marketing strategy.

Keywords: fashion involvement; positive emotion; hedonism; impulsive buying.
\end{abstract}




\section{PENDAHULUAN}

Dewasa ini, globalisasi menjadi salah satu faktor meningkatnya perkembangan perekonomian Indonesia. Globalisasi dalam konteks ekonomi adalah serangkaian proses kegiatan produksi dan konsumsi yang bergeser dari skala nasional ke skala global. Hal ini bisa dilihat dari meningkatnya aktivitas perdagangan internasional, investasi asing, dan aktivitas perusahaan multinasional yang terwujud dari perkembangan komunikasi global yang menyebabkan banyaknya perminaan barang konsumtif di tiap negara (O'Brien \& Leichenko, 2000). Faktor pendorong arus globalisasi ekonomi adalah semakin terbukanya sistem perekonomian negara-negara di dunia baik dalam perdagangan, industri maupun keuangan (Fukuyama, 2000). Perkembangan bisnis di Indonesia juga berpengaruh signifikan karena globalisasi. Hal ini mengundang perusahaan luar negeri dengan kekuatan kapitalisnya untuk ber-ekspansi ke Indonesia melihat tingginya mobilitas masyarakat urban yang cenderung konsumtif.

Perlu diketahui bahwa faktor persaingan adalah hal penting yang harus diperhatikan. Brosekhan \& Velayutham (2013) berpendapat dengan mengetahui tentang perilaku konsumen akan membantu pemasar mengetahui bagaimana karakter konsumen dalam berbelanja maupun bagaimana ia dipengaruhi oleh tren, lingkungan, keluarga, salesperson dan sebagainya. Konsumen memiliki daya belinya masing-masing, selera, dan tingkat kecerdasan dalam memilih barang pilihannya hingga terjadinya keputusan dan evaluasi pembelian yang dinamakan aktivitas pre-purchase dan post-purchase. Proses pembelian ini ditemui kapanpun dan dimanapun oleh konsumen ketika mereka menelaah dahulu antara butuh atau tidaknya produk yang akan dibeli dan sedikit evaluasi informasi sampai ketika konsumen telah memiliki produk tersebut dan mengevaluasi kembali untuk mengurangi kecemasan terhadap barang tersebut. Namun, ada juga kalanya proses pembelian yang dilakukan konsumen tanpa melewati proses pre-purchase yaitu pembelian tanpa rencana atau yang umumnya disebut dengan impulsive buying. Dengan melakukan strategi berdasarkan materi dari faktor-faktor yang menyebabkan impulsive buying dan menerapkan sesuai keadaan sekitar, pebisnis dapat meningkatkan minat beli konsumen dan mendatangkan perusahaan pendapatan yang tinggi.

Rook \& Fisher (1995) mendefinisikan pembelian impulsif sebagai kecenderungan konsumen untuk membeli secara spontan, reflek, tiba-tiba dan otomatis. Dari definisi tersebut terlihat bahwa perilaku impulsif merupakan sesuatu yang alamiah dan merupakan reaksi yang sangat cepat. Konsumen sering distimulasi oleh pebisnis agar melakukan pembelian impulsif. Hal itu bisa muncul dari diri sendiri, produk, suasana gerai, dan sebagainya. Di era globalisasi ini banyak kasus terjadi ketika konsumen membeli suatu barang atau jasa bukan karena faktor kebutuhan lagi. Tjiptono (2002) mengatakan faktor penting konsumen terhadap perilaku konsumsi yakni para konsumen memperhatikan makna tertentu selain manfaat fungsionalnya, semisal bergantung kepada kepribadian, citra diri, bahkan ukuran gengsi-nya. Pada kawasan berkembang yag cenderung konsumtif seperti Bali, merk produk yang merefleksikan citra diri seseorang sangat diminati oleh masyarakat. 
Scarpi (2006) hedonisme berasal dari bahasa Yunani yaitu hedone yang artinya kesenangan atau kenikmatan. Konsumsi hedonik mencerminkan nilai pengalaman berbelanja seperti fantasi, arousal, stimulasi-sensori, kenikmatan, kesenangan, keingintahuan, dan hiburan. Menurut Dhurup (2014) nilai belanja hedonis jauh lebih subjektif, personal, berpengalaman daripada manfaat lainnya. Arnold \& Reynolds (2003) mendefinisikan ada 6 jenis faktor motivasi konsumsi hedonis: 1) Adventure Shopping. Hal ini mengacu pada belanja untuk stimulasi, petualangan, dan perasaan berada di dunia lain. Sering digambarkan pengalaman belanja dalam hal pertualangan, sensasi, stimulasi, kegembiraan, dan memasuki dunia berbeda dalam melihat hal menarik, bau, dan suara. 2) Social Shopping. Mengacu pada kenikmatan berbelanja dengan teman-teman dan keluarga, bersosialisasi saat berbelanja, dan ikatan dengan orang lain saat berbelanja. 3) Gratification Shopping. Mengacu pada berbelanja untuk menghilangkan stres, belanja untuk meringankan suasana hati yang negatif, dan belanja sebagai hadiah khusus untuk diri sendiri. 4) Idea Shopping. Mengacu pada berbelanja untuk mengikuti tren dan mode baru. Agar konsumen juga tetap sejajar dengan produk terbaru dan inovasi yang tersedia. 5) Role Shopping. Mengacu pada konsumen merasakan kesenangan jika berbelanja untuk orang lain daripada dirinya sendiri. konsumen merasakan kegembiraan dan sukacita ketika menemukan hadiah yang sempurna untuk orang lain. 6) Value Shopping. Mengacu pada berbelanja untuk mencari diskon, dan hunting untuk tawar-menawar. Menjadi sebuah tantangan tersendiri

O'Cass (2004) Pergeseran kebutuhan manusia akan hal berpakaian tidak lagi hanya berdasarkan kebutuhan sehari-hari sebagai pelindung badan, namun sekarang menyesuaikan citra diri tiap individu dan merupakan hal penting jika mampu memberikan rasa atas pengakuan jati diri kepada masyarakat. Orientasi konsumen dalam pakaian bergeser dari yang awalnya sebagai kebutuhan, menjadi yang meningkatkan penampilan, sebagai identitas individu serta yang ada hubungannya dengan gaya hidup atau lebih sering disebut fashion. Fashion adalah industri miliaran dollar yang telah membuka banyak lapangan pekerjaan bagi masyarakat dipenjuru dunia. Sejak ekonomi semakin global, kita menyadari perubahan fashion dirasa cepat berganti kususnya sangat mempengaruhi konsumen yang hobi terhadap fashion. Pengecer besar telah mendominasi bisnis pakaian fashion sejak akhir 1980an. Selama beberapa dekade terakhir, industri fashion banyak memberikan dampak dan konstribusi. Fashion merefleksikan lingkungan dan budaya kita, juga mencerminkan karakter kita sediri. Ketika fashion sebenarnya mencakup keseluruhan, masyarakat umumnya menganggap fashion dengan pakaian dan aksesoris. Fashion dapat ditemukan pada seluruh aktivitas harian manusia, yang pada umunya mereka juga mempunyai jangka waktu musiman sendiri (Holmberg \& Ohnfeldt, 2010). Pada penelitian ini, fashion yang dimaksud juga mengerucut pada pakaian dan aksesoris. Industri fashion saat ini sangatlah kompetitif dimana pergerakannya sangat cepat yang mengharuskan pengecer selalu memperbarui produknya tiap pergantian musim. Pengecer seperti Zara dan H\&M mendorong minat konsumennya dengan menggunakan strategi "here today, gone tomorrow" dimana dengan stok yang tidak banyak, mereka dapat memperbarui koleksi fashion nya agar display cepat berganti beserta trik pemasaran seperti memberikan diskon atau kesan "limited edition" (Bhardwaj dan Fairhurst, 2010). 
Park et al., (2006) fashion involvement digunakan untuk meramalkan variabel tingkah laku yang berhubungan dengan produk pakaian seperti keterlibatan produk, perilaku pembelian, dan karakteristik pribadi seseorang. Aryadini (2012) merk merupakan sebuah identitas dan label kepemilikan suatu produk, bahkan sekarang konsumen menggunakan merk sebagai petunjuk dalam memutuskan pembelian seperti halnya mereka ingin berbelanja karena alasan merk tersebut. Pada penelitian ini, penulis menggunakan konsumen merk Zara karena produk fashion tersebut dianggapnya mampu memberikan value lebih dan kesan eksklusif bagi pemakainya. Tampilan pakaian dan aksesoris Zara sekilas sudah sangat meyerupai produk fashion kelas designer dunia yang identik dengan kemewahan yang mampu meningkatkan citra diri bagi para pemakainya. Dengan produk fashion ter-update, merk ini berhasil melengkapi permintaan pasar dengan mengeluarkan desain baru di gerainya per 15 hari dari panggung fashion show. Hal ini sudah sangat valid dengan pola masyarakat modern konsumtif yang mempunyai spending behavior tinggi akibat dampak globalisasi. Masyarakat yang hobi fashion pun juga menjadi sasaran empuk selanjutnya. Han et al., (1991) fashion involvement mendorong impulsive buying dengan memberikan insyarat sensori atau pengalaman produk fashion. Zara adalah merk produk fashion asal Spanyol yang telah membuka cabangnya di berbagai penjuru dunia termasuk di Bali. Hausman (2000) impulsive buying dapat diprediksi oleh variabel penting lainnya seperti kecenserungan konsumsi hedonis dan emosi positif. Hal ini sangat penting pemasar memahami impulsive buying dari perspektif pengalaman belanja. Melihat banyaknya fenomena seperti uraian diatas, penulis memilih untuk menggunakan judul penelitian "Fashion Involvement mempengaruhi Emosi Positif dan Hedonisme terhadap Impulsive Buying di gerai Zara Bali”

Perilaku konsumen adalah kegiatan-kegiatan individu yang secara langsung terlibat dalam mendapatkan dan mempergunakan barang dan jasa, termasuk di dalamnya proses pengambilan keputusan pada persiapan dan penentuan kegiatankegiatan tersebut (Kotler \& Amstrong, 2012). Peter \& Olson (2005)mengatakan perilaku konsumen adalah interaksi yang terus berubah pada tiap konsumen dalam hal pikiran, perilaku dan kejadian sekitar. Konsumen saling bertukar aspek pada hidup mereka. Kotler \& Amstrong (2012) menjelaskan proses pengambilan keputusan yaitu pengenalan masalah, pencarian informasi, evaluasi alternatif, keputusan pembelian, dan perilaku pasca pembelian. Pada tahap pertama (pengenalan masalah) ini Hal ini terjadi ketika adanya keinginan menyelesaikan masalah dimana ada rasa pemenuhan kebutuhan dan ditemukan hal yang ideal untuk konsumen daripada yang terjadi sebenarnya. Tahap kedua adalah pencarian informasi dimana sumber informasi yang didapat berasal dari perorangan, iklan, publik, dan pengalaman. Selanjutnya tahap ketiga, melakukan evaluasi alternatif kepada konsumen seperti me-review produk dan jasa apakah mampu mengatasi masalah dan melengkapi kebutuhan mereka. Akhir tahap ini adalah timbul kecenderungan konsumen untuk membeli merk tertentu. Tahap keempat yaitu konsumen memutuskan pembelian dan terbagi menjadi tiga tipe yaitu extended decision making, limited decision making, dan habitual decision making (Hawkins et al., 1992). Tahap terakhir adalah tahap pasca pembelian meliputi tahap kepuasan pasca pembelian, tahap tindakan pasca pembelian, dan tahap penggunaan dan pembuanan pasca 
pembelian. Hausman (2000) menyatakan perilaku pembelian dari segi perencanaan dibagi dua yaitu pembelian yang direncanakan dan pembelian yang tidak direncanakan.

Fashion Involvement pada setiap karakter seperti remaja, wanita, atau pria mempunyai pengetahuan tersendiri melihat fashion. Pengetahuan ini mempengaruhi konsumen merasa percaya diri pada pengambilan keputusan pembelian (O'Cass, 2000). Pengetahuan konsumen sangat bervariasi tentang fashion dan mereka mempunyai cara sendiri mengenali produk-produknya. Pengetahuan tersebut datang dari product experiences, paparan iklan, interaksi dengan penjual, teman, media, keputusan sebelumnya. Fashion Involvement berfungsi untuk memperkirakan variabel tingkah laku pada hal-hal yang serupa dengan pakaian itu sendiri seperti keterlibatan produk, perilaku belanja konsumen, dan karakteristik konsumen. Hal serupa juga ada hubungannya dengan seseorang yang mengerti dan mengikuti tren fashion, hal tersebut otomatis mempengaruhi keputusan pembelian mereka. Maka dari itu dikemukakan bahwa konsumen yang memiliki keterlibatan fashion tinggi akan lebih terlibat dalam impulse buying berorientasi pada fashion (O'Cass, 2004).

Laros \& Steenkamp (2005) emosi adalah reaksi penilaian dari sistem saraf seseorang terhadap rangsangan eksternal atau internal dan sering dikonseptualisasikan sebagai sebuah dimensi yang umum, seperti yang mempengaruhi positif dan negatif. Psikolog sering menggunakan istilah mempengaruhi ketika mengacu pada emosi atau perasaan. Mereka diklasifikasikan ke dalam dua dimensi, emosi positif dan negatif. Perasaan dapat dikonsepkan sebagai pengaruh positif emosi positif, yang mencerminkan sejauh mana seseorang merasa antusias, aktif, dan waspada. Ini adalah kondisi energi tinggi, konsentrasi penuh dan keterlibatan menyenangkan (Baron \& Byrne, 2003). Sedangkan menurut Cabanac (1971) emosi positif meliputi komponen dari pengaruh positif, emosi positif menyebar fungsi dari keadaan afektif lainnya. Misalnya sensori kesenangan, memotivasi orang untuk melakukan apapun yang besifat stimulus pada saat itu. Emosi positif datang dari perasaan yang ada sebelumnya. Seperti ketika seseorang melihat ada promosi pada produk A, orang tersebut mempunyai emosi positif terhadap produk A lalu mengambil tindakan.

Piron (1993) keputusan pembelian sangat bisa terjadi dari apa yang pada saat itu konsumen itu sedang rasakan. Perasaan akan puas, memicu terjadinya pengalaman hedonik pada saat berbelanja, muncul-lah emosi positif. Pembelian impulsif juga memiliki hubungan positif dengan instrumen kegembiraan, perasaan jatuh cinta, merasa memiliki, dan percikan antusias. Emosi positif lebih mudah dirasakan karena perasaan tersebut sudah dimiliki tiap individu, bisa lebih ditingkatkan reaksinya pada saat ada di lingkungan belanja konsumen. Emosi juga bereaksi besar kepada tindakan impulse buying (Beatty \& Farrell, 1998). Ketika dibandigkan dengan emosi negatif, konsumen dengan emosi positif menunjukkan impulsive buying yang lebih baik dikarenakan perasaan yang tak terbatasi, hasrat ingin me reward dirinya sendiri dan tingkat energi yang lebih tinggi (Rook \& Gardner, 1993).

Hirschman \& Holbrook (1982) ketika seseorang atau konsumen memiliki involvement dalam arti refleks orientasi maka komponen gairah mungkin akan 
menjadi lebih erat kaitannya dengan fenomena otak kanan yang berhubungan dengan emosi. Hasil penemuan yang dilakukan Aryadini (2012) menunjukkan fashion involvement berpengaruh secara positif terhadap emosi positif karena konsumen sudah mempunyai bayangan tentang produk yang ingin dibelanjakan. Hal serupa juga ditemukan Ismayuni \& Saraswati (2015) bahwa fashion involvement berpengatuh positif terhadap emosi positif dari hasil secara keseluruhan bahwa penilaian emosi positif pada produk Nike sudah baik karena rata-rata konsumen merasa senang, puas dan mempengaruhi suasana hati pada saat berbelanja produk Nike. Berdasarkan pemahaman diatas, dapat dirumuskan hipotesa pertama:

$\mathrm{H}_{1}$ : Fashion Involvement berpengaruh positif terhadap Emosi Positif

Pada penelitian yang dilakukan Park et al. (2006) bahwa konsumen memiliki involvement yang tinggi pada fashion terbaru, konsumen berbelanja untuk memenuhi kebutuhan fashion, konsumen mencoba merias diri mereka dengan fashion artinya ada kecenderungan hedonik seperti rasa ingin tahu untuk mengeksplorasi dunia baru selama mereka berbelanja. Hasil penelitian Herlambang S (2008) juga menunjukkan hipotesis yang diajukan pada pelanggan Matahari department store bahwa fashion involvement berpengaruh secara positif mempengaruhi konsumsi hedonik. Didukung juga dari hasil temuan Hermanto (2016) yang melakukan penelitian di kota Surabaya diterima secara positif bahwa bahwa fashion involvement mempunyai pengaruh yang signifikan terhadap motivasi belanja hedonis karena konsumen akan berusaha memenuhi kebutuhan fashion mereka dengan berpenampilan up to date dan menarik agar bisa dipamerkan. Berdasarkan pemahaman tersebut, dapat dirumuskan hipotesis kedua:

$\mathrm{H}_{2}$ : Fashion Involvement berpengaruh positif terhadap Hedonisme

Han et al. (1991) mendapatkan bahwa mahasiswa di bidang tekstil dan fashion memiliki skor dalam pembelian impulsif lebih tinggi dibandingkan pada mahasiswa yang di bidang atau jurusan lain. Temuan ini mendukung gagasan bahwa keterlibatan fashion mendorong terjadinya pembelian impulsif dengan memberikan isyarat sensorik atau pengalaman mengenai produk fashion. Hasil temuan Zakiar (2010) juga mendapatkan adanya pengaruh dari fashion involvement terhadap pembelian impulsif pada produk fashion di Jakarta. Begitu juga dengan hasil dari Erlina (2015) bahwa keterlibatan fashion berpengaruh terhadap impulsive buying mahasiswa Strata 1 Manajemen Fakultas Ekonomi Universitas Jember dan dapat diterima. Kesimpulan dari penelitian tersebut bahwa para mahasiswi lebih peka dengan atribut-atribut fashion terhadap keputusan impulsive buying. Berdasarkan pemahaman tersebut, dapat dirumuskan hipotesa ketiga:

$\mathrm{H}_{3}$ : Fashion Involvement berpengaruh positif terhadap Impulsive Buying

Hausman (2000) mengemukakan pengalaman berbelanja hedonis ada kaitannya dengan perasaan positif konsumen seperti kesenangan dan merupakan aspek baru dalam belanja hedonis. Hal serupa juga dikatakan Hirschman \& Holbrook (1982) bahwa konsumsi hedonis sudah memenuhi semua syarat multisensori, fantasi, kebahagiaan dan perasaan senang dalam penggunaan suatu produk - pengaruh dari emosi tersebut. Hasil penelitian yang dilakukan Park et al. (2006) konsumsi berbelanja hedonis berpengaruh signifikan terhadap emosi positif. Konsumen lebih merasa semangat dan puas pada saat berbelanja ketika mereka bisa mengekspresikan keingintahuan, kebutuhan akan hal baru, dan perasaan 
seperti mereka menjelajahi dunia baru. Berdasarkan pemahaman tersebut, dapat dirumuskan hipotesa keempat:

$\mathrm{H}_{4}$ : Hedonisme berpengaruh signifikan terhadap Emosi Positif

Hausman (2000) menemukan bahwa konsumen yang berbelanja untuk memuaskan keinginan hedonisnya seperti mencari pengalaman baru, mencari variasi dan kesenangan ternyata secara signifikan berpengaruh terhadap impulse buying. Rohman (2009) menemukan konsumsi hedonis berpengaruh secara positif terhadap impulsive buying pada produk fashion. Hal serupa juga didukung dari penemuan yang dilakukan oleh Anjani (2012) bahwa konsumsi hedonik berpengaruh positif terhadap pembelian impulsif produk fashion di depertment store. Berdasarkan pemahaman tersebut, dapat dirumuskan hipotesa kelima:

$\mathrm{H}_{5}$ : Hedonisme berpengaruh positif terhadap Impulsive Buying

Rook \& Fisher (1995) mendapatkan bahwa konsumen yang memiliki emosi positif akan melakukan pembelian impulsif yang lebih tinggi, hal ini dikarenakan oleh perasaan yang tak terbatas, keinginan untuk me-reward diri mereka sendiri dan frekuensi yang lebih atas. Hasil penemuan dari Dhurup (2014) juga mendapatkan pengaruh positif bahwa impulsive buying didorong dari tingkat emosional kepuasan para siswa saat berbelanja. Hal ini juga didukung penemuan dari Putra \& Mudiantono (2014) bahwa pembelian impulsif terjadi karena dipengaruhi oleh emosi positif dan variabel lainnya pada penelitian terhadap konsumen yang dilakukan di swalayan Tong Hien. Berdasarkan pemahaman tersebut, dapat dirumuskan hipotesa keenam:

$\mathrm{H}_{6}$ : Emosi Positif berpengaruh secara positif terhadap Impulsive Buying

\section{METODE PENELITIAN}

Penelitian ini adalah penelitian kuantitatif yang menggunakan 1 (satu) variabel bebas, 3 (tiga) variabel terikat. Variabel yang digunakan dalam penelitian ini adalah variabel terikat (dependent) yaitu emosi positif, hedonisme, dan impulsive buying, variabel bebas (independent) yaitu fashion involvement. Sampel yang digunakan dalam penelitian ini diambil dengan menggunakan metode Accidental Sampling atau sampling insidental dimana teknik penentuan sampel berdasarkan kebetulan, yaitu siapa saja yang secara kebetulan/insidental bertemu dengan peneliti dapat digunakan sebagai sampel, bila dipandang orang yang kebetulan ditemui itu cocok dengan sumber data (Sugiyono, 2012:96). Adapun pertimbangan yang digunakan dalam pengambilan sampel adalah sebagai berikut: 1). Responden yang menetap dan bertempat tinggal di Bali. 2). Responden yang berusia 17 tahun keatas.

Untuk memperoleh hasil yang valid dari kuisioner, diperlukan jumlah sampel responden yang diambil untuk mengisi kuisioner dapat ditentukan paling sedikit (5-10) x jumlah variabel yang diteliti. Penelitian ini menggunakan 17 indikator sehinggan jumlah responden yang digunakan sabagai sampel dalam penelitian ini adalah $17 \times 5=85$ responden. Teknik analisis data yang digunakan pada penelitian ini adalah teknik Partial Least Square (PLS) sebuah teknik pemodelan struktural yang sangat sesuai dengan model penelitian kompleks yang melibatkan banyak konstruk dan indikator (Hair et al., 2011) 


\section{HASIL DAN PEMBAHASAN}

Tabel 1.

Karakteristik Responden

\begin{tabular}{|c|c|c|c|}
\hline No & $\begin{array}{l}\text { Karakteristik Re- } \\
\text { sponden }\end{array}$ & Keterangan & Jumlah Orang \\
\hline \multirow{2}{*}{1} & \multirow{2}{*}{ Jenis Kelamin } & Pria & 23 \\
\hline & & Wanita & 62 \\
\hline \multirow{5}{*}{2} & \multirow{5}{*}{ Usia } & & 85 \\
\hline & & $18-25$ & 50 \\
\hline & & $26-33$ & 25 \\
\hline & & $34-41$ & 6 \\
\hline & & $>41$ & 5 \\
\hline \multicolumn{3}{|c|}{ Jumlah } & 85 \\
\hline \multirow{5}{*}{3} & \multirow{5}{*}{ Pekerjaan } & Pelajar / Mahasiswa & 32 \\
\hline & & Pegawai Swasta & 18 \\
\hline & & Pegawai Negeri & 6 \\
\hline & & Wiraswasta & 19 \\
\hline & & Lainnya & 11 \\
\hline \multirow{6}{*}{4} & \multirow{5}{*}{ Anggaran Belanja } & & 85 \\
\hline & & $<500.000,-$ & 16 \\
\hline & & $600.000-1.200 .000,-$ & 48 \\
\hline & & $1.300 .000-1.600 .000$ & 15 \\
\hline & & $>1.700 .000$ & 6 \\
\hline & \multirow{4}{*}{ Frekuensi Belanja } & & 85 \\
\hline \multirow{4}{*}{5} & & 1 kali & 15 \\
\hline & & $2-4$ kali & 46 \\
\hline & & $>5$ kali & 24 \\
\hline & \multicolumn{2}{|c|}{ Jumlah } & 85 \\
\hline
\end{tabular}

Sumber: Data diolah, 2016

Data diatas menunjukkan bahwa sebanyak 23 responden adalah pria, dan 62 responden adalah wanita. Usia responden didominasi dengan responden berusia 18-25 sebanyak 50 orang, 26-33 sebanyak 25 responden, 34 sampai 41 sebanyak 4 responden dan yang berusia diatas 41 sebanyak 5 responden. Hal ini berarti rata- 
rata responden terbanyak berasal dari golongan berumur 18-25. Pekerjaan responden terbanyak berasal dari kalangan pelajar / mahasiswa sebanyak 32 responden, pegawai swasta sebanyak 18 responden, pegawai negeri sebanyak 6 responden, wiraswasta berjumlah 19 responden, dan lainnya sejumlah 11 responden. Anggaran belanja responden per sekali belanja dari 500.000,- kebawah sebanyak 16 responden, $600.000-1.200 .000$ sebanyak 48 responden, $1.300 .000-1.600 .000$ sebanyak 15 responden dan diatas dari 1.700 .000 sebanyak 6 responden. Dan frekuensi belanja responden dalam 3 bulan terakhir yang berjumlah 1 kali sebanyak 15 responden, 2 sampai 4 kali sebanyak 46 responden dan diatas 5 kali sebanyak 24 responden.

Tabel 2.

Uji Validitas

\begin{tabular}{|c|c|c|c|c|}
\hline No & Variabel & Indikator & $\begin{array}{l}\text { Pearson Corre- } \\
\text { lation (r) }\end{array}$ & Keterangan \\
\hline \multirow{4}{*}{1} & \multirow{4}{*}{ Fashion Involvement } & Inv.1 & 0,913 & Valid \\
\hline & & Inv. 2 & 0,881 & Valid \\
\hline & & Inv. 3 & 0,913 & Valid \\
\hline & & Inv. 4 & 0,809 & Valid \\
\hline \multirow{3}{*}{2} & \multirow{3}{*}{ Emosi Positif } & Ems. 1 & 0,924 & Valid \\
\hline & & Ems. 2 & 0,913 & Valid \\
\hline & & Ems.3 & 0,912 & Valid \\
\hline \multirow{6}{*}{3} & \multirow{6}{*}{ Hedonisme } & Hed.1 & 0,863 & Valid \\
\hline & & Hed.2 & 0,907 & Valid \\
\hline & & Hed.3 & 0,839 & Valid \\
\hline & & Hed.4 & 0,866 & Valid \\
\hline & & Hed.5 & 0,643 & Valid \\
\hline & & Hed.6 & 0,650 & Valid \\
\hline \multirow{4}{*}{4} & \multirow{4}{*}{ Impulsive Buying } & Imp.1 & 0,760 & Valid \\
\hline & & $\operatorname{Imp} .2$ & 0,797 & Valid \\
\hline & & Imp.3 & 0,875 & Valid \\
\hline & & Imp.4 & 0,867 & Valid \\
\hline
\end{tabular}

Sumber: Data diolah, 2016

Hasil reliabilitas terhadap intrumen penelitian ini menggunakan nilai Alpha Cronbach untuk mengetahui unimensionalitas butir-butir pertanyaan terhadap variabel laten yang diteliti dengan tingkat $\alpha=0,05$. Nilai Alpha Cronbach dinyatakan realibel ketika nilainya lebih besar atau sama dengan 0,60 (Ghozali, 2008). Rekapitulasi uji reabilitas instrumen penelitian dapat dilihat pada Tabel 3. 
Tabel 3.

Uji Relialibilitas

\begin{tabular}{|c|c|c|c|}
\hline No & Variabel & Alpha Cronbach & Keterangan \\
\hline 1 & Fashion Involvement & 0,901 & Realibel \\
\hline 2 & Emosi Positif & 0,901 & Realibel \\
\hline 3 & Hedonisme & 0,886 & Realibel \\
\hline 4 & Impulsive Buying & 0,842 & Realibel \\
\hline
\end{tabular}

Sumber: Data diolah, 2016

Sebelum membahas signifikansi pengaruh langsung masing-masing variabel eksogen terhadap endogen dalam model penelitian, terlebih dahulu dibahas validasi model. Terdapat tiga kriteria dalam penggunaan teknik analisis data dengan SmartPLS untuk menilai outer model yaitu convergent validity, discriminant validity, serta average variance excracted (AVE) dan composite reability (Ghozali, 2008). Penggunaan teknik analisis data menggunakan PLS, outer model dinilai dengan cara melihat convergent validity (besarnya loading factor untuk masingmasing konstruk). Penelitian ini menggunakan batas minimal loading factor sebesar 0,5

Tabel 4.

Outter Loading

\begin{tabular}{ccccc}
\hline No & $\begin{array}{c}\text { Fashion Involve- } \\
\text { ment }\end{array}$ & Emosi Positif & Hedonisme & Impulsive Buying \\
\hline X1 & 0,879 & & & \\
X2 & 0,846 & & & \\
X3 & 0,876 & & & \\
X4 & 0,768 & & & \\
Y1.1 & & 0,910 & & \\
Y1.2 & & 0,917 & & \\
Y1.3 & & 0,842 & 0,822 & \\
Y2.1 & & 0,760 & \\
Y2.2 & & 0,854 & \\
Y2.3 & & & 0,860 & 0,838 \\
Y2.4 & & 0,736 & 0,822 \\
Y2.5 & & & 0,701 & 0,876 \\
Y2.6 & & & & 0,904 \\
Y3.1 & & & & \\
Y3.2 & & & & \\
Y3.3 & & & & \\
Y3.4 & & & \\
\hline
\end{tabular}

Sumber: Data diolah, 2016

Seperti yang ditunjukkan tabel diatas yang memperlihatkan nilai outer model telah memenuhi kriteria convergent validity dimana semua indikator memiliki loading factor diatas 0,50. Bisa disimpulkan bahwa konstruk mempunyai convergent validity yang baik.

Discriminant validity dari model pengukuran dengan reflektif indikator dinilai berdasarkan crossloading pengukuran dengan konstruk. Jika korelasi konstruk dengan item pengukuran lebih besar daripada ukuran konstruk lainny, maka 
hal ini menunjukkan bahwa konstruk laten memprediksi ukuran pada blok mereka lebih baik daripada ukuran pada blok lainnya.

Tabel 5.

Crossloading

\begin{tabular}{ccccc}
\hline No & $\begin{array}{c}\text { Fashion Involve- } \\
\text { ment }\end{array}$ & Emosi Positif & Hedonisme & Impulsive Buying \\
\hline X1 & 0,879 & 0,632 & 0,567 & 0,619 \\
X2 & 0,846 & 0,642 & 0,611 & 0,704 \\
X3 & 0,876 & 0,610 & 0,488 & 0,606 \\
X4 & 0,768 & 0,550 & 0,473 & 0,571 \\
Y1.1 & 0,629 & 0,910 & 0,537 & 0,674 \\
Y1.2 & 0,672 & 0,917 & 0,610 & 0,710 \\
Y1.3 & 0,630 & 0,842 & 0,612 & 0,680 \\
Y2.1 & 0,597 & 0,595 & 0,822 & 0,690 \\
Y2.2 & 0,545 & 0,471 & 0,760 & 0,529 \\
Y2.3 & 0,541 & 0,599 & 0,854 & 0,612 \\
Y2.4 & 0,543 & 0,593 & 0,860 & 0,613 \\
Y2.5 & 0,372 & 0,446 & 0,736 & 0,542 \\
Y2.6 & 0,389 & 0,380 & 0,701 & 0,508 \\
Y3.1 & 0,560 & 0,573 & 0,635 & 0,838 \\
Y3.2 & 0,614 & 0,685 & 0,639 & 0,882 \\
Y3.3 & 0,690 & 0,725 & 0,683 & 0,876 \\
Y3.4 & 0,731 & 0,714 & 0,638 & 0,904 \\
\hline
\end{tabular}

Sumber: Data diolah, 2016

Hasil dari Tabel 5. menjelaskan nilai cross loading menunjukkan adanya discriminant validity yang baik. Hal tersebut bisa dilihat dari nilai korelasi indikator terhadap loading factor lebih tinggi dibandingkan nilai korelasi indikator tersebut dengan konstruk lainnya.

Reabilitas suatu konstruk dapat dinilai dari composite reability yang berfungsi mengukur internal consistency yang lainnya harus diatas 0,60 dan membandingkan akar AVE dengan korelasi antar konstruk dengan nilai harus diatas 0,50

Tabel 6.

Composite Reliability

\begin{tabular}{lc}
\hline \multicolumn{1}{c}{ Variabel } & Composite Reability \\
\hline Fashion Involvement & 0,908 \\
Emosi Positif & 0,920 \\
Hedonisme & 0,909 \\
Impulsive Buying & 0,929
\end{tabular}

Sumber: Data diolah, 2016

Tabel 6. menunjukkan bahwa nilai composite reliability dari semua konstruk memiliki nilai diataas 0,60 maka dianggap memiliki kriteria reliabel. Cara lain menguji reliabilitas adalah dengan membandingkan nilai akar dari Average Variance Extracted (AVE) setiap kontruk dengan korelasi antar konstruk dalam model penelitian. 
Tabel 7.

Nilai AVE

\begin{tabular}{lll}
\hline \multicolumn{1}{c}{ Variabel Laten } & AVE & $\sqrt{A V E}$ \\
\hline Fashion Involvement & 0,712 & 0,844 \\
Emosi Positif & 0,793 & 0,891 \\
Hedonisme & 0,626 & 0,792 \\
Impulsive Buying & 0,767 & 0,876 \\
\hline
\end{tabular}

Sumber: Data diolah, 2016

Akar AVE pada tabel diatas akan dibandingkan dengan nilai korelasi antar variabel bebas seperti ditunjukkan pada tabel 8 .

Tabel 8.

Korelasi antar Variabel Laten

\begin{tabular}{lcccc}
\hline & $\begin{array}{c}\text { Fashion In- } \\
\text { volvement }\end{array}$ & Emosi Positif & Hedonisme & Impulsive Buying \\
\hline Fashion Involvement & 1.000 & 0,724 & & \\
Emosi Positif & & 1.000 & & \\
Hedonisme & 0.638 & 0.660 & 1.000 & \\
Impulsive Buying & 0.745 & 0.774 & 0.741 & 1.000 \\
\hline
\end{tabular}

Sumber: Data diolah, 2016

Tabel 8. menunjukkan bahwa akar AVE setiap konstruk jauh lebih besar daripada nilai korelasi konstruk tersebut dengan konstruk lainnya sehingga dapat dikatakan bahwa data sudah reliabel.

Inner model menggabarkan hubungan antar variabel laten berdasarkan pada substantive theory. Dalam menilai model dengan menggunakan PLS, dimulai dengan melihat R-squae untuk setiap variabel laten dependen. Hasil pengujian inner model dapat melihat hubungan antar konstruk dengan cara membandingkan nilai signifikansi dan R-square dari model penelitian (Ghozali, 2008).

Tabel 9.

Nilai $R$-square

\begin{tabular}{lc}
\hline & $\boldsymbol{R}$ square \\
\hline Fashion Involvement & - \\
Emosi Positif & 0,580 \\
Hedonisme & 0,400 \\
Impulsive Buying & 0,716 \\
\hline
\end{tabular}

Sumber: Data diolah, 2016

Nilai $R$-square emosi positif sebesar 0,580 dapat diintepretasikan bahwa $58 \%$ variabilitas konstruk emosi positif dijelaskan oleh variabel fashion involvement, sedangkan $42 \%$ variabel emosi positif dijelaskan oleh variabel diluar model. Demikian juga variabel hedonisme sebesar 0,400 dapat diintepretasikan bahwa $40 \%$ variabilitas konstruk hedonisme dijelaskan oleh variabel fashion involvement sedangkan $60 \%$ nya dijelaskan oleh variabel diluar model. Demikian juga dengan variabel impulsive buying sebesar 0,716 dapat diintepretasikan bahwa 71,60\% 
varibialitas konstruk impulsive buying dijelaskan oleh variabel fashion involvement, emosi positif, dan hedonisme sedangkan $28.4 \%$ variabilitas konstruk impulsive buying dijelaskan oleh variabel diluar fashion involvement.

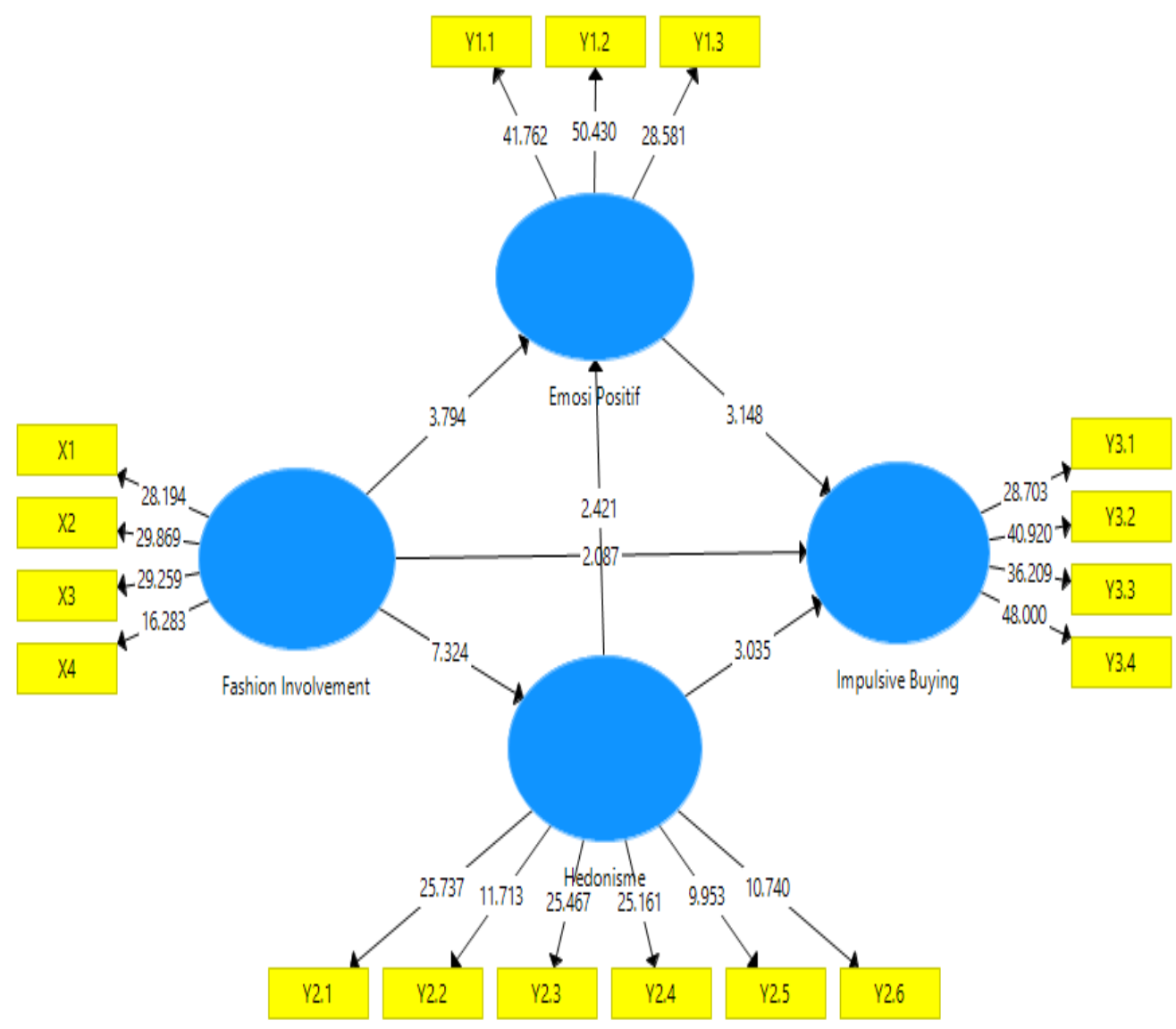

Gambar 1. Diagram Jalur Hipotesis (bootstrap)

Sumber: Data diolah, 2016

Model struktural tersebut disebut model refleksif dimana covariance pengukuran indikator dipengaruhi oleh konstruk laten atau mencerminkan variasi dari konstruk undimensional. Model ini menghipotesiskan bahwa perubahan pada konstruk laten akan mempengaruhi perubahan pada indikator. Dalam model tersebut terdapat satu konstruk eksogen yaitu variabel fashion involvement serta tiga variabel endogen yaitu emosi positif, hedonisme, dan impulsive buying. Keempat konstruk memiliki indikator masing-masing.

Pengujian hipotesis tentang koefisien jalur atau pengaruh fashion involvement, emosi positif, dan hedonisme terhadap impulsive buying disajikan pada Tabel 10. 
Tabel 10.

Hasil Inner Loading

$\begin{array}{ccccc}\text { Original } & \text { Sample } & \text { Standard } & & \\ & \text { Mean } & \text { Deviation } & \text { TStatistics } & \text { P Values } \\ \text { Sample } & (M) & (\text { STDEV }) & (\text { STERR }) & \\ & & & & \end{array}$

\begin{tabular}{|c|c|c|c|c|c|}
\hline $\begin{array}{l}\text { Fashion Involvement } \\
\text {-> Emosi Positif }\end{array}$ & 0,511 & 0,505 & 0,135 & 3,794 & 0,000 \\
\hline $\begin{array}{l}\text { Fashion Involvement } \\
\text {-> Hedonisme }\end{array}$ & 0,638 & 0,646 & 0,087 & 7,324 & 0,000 \\
\hline $\begin{array}{l}\text { Fashion Involvement } \\
\text {-> Impulsive Buying }\end{array}$ & 0,277 & 0,292 & 0,133 & 2,087 & 0,037 \\
\hline $\begin{array}{l}\text { Emosi Positif -> Im- } \\
\text { pulsive Buying }\end{array}$ & 0,356 & 0,335 & 0,113 & 3,148 & 0,002 \\
\hline $\begin{array}{l}\text { Hedonisme -> Emosi } \\
\text { Positif }\end{array}$ & 0,334 & 0,341 & 0,138 & 2,421 & 0,016 \\
\hline $\begin{array}{l}\text { Hedonisme -> Impul- } \\
\text { sive Buying }\end{array}$ & 0,330 & 0,333 & 0,109 & 3,035 & 0,002 \\
\hline
\end{tabular}

Sumber: Data diolah, 2016

Pengujian hipotesis dalam metode PLS dilakukan dengan menggunakan simulasi simulasi terhadap setiap hubungan yang dihipotesiskan, dalam hal ini dilakukan metode bootstrap. Metode bootstrap juga berfungsi untuk meminimalkan ketidaknormalan data penelitian. Pada riset ini sebelumnya telah ditentukan nilai T-tabel dengan signifikansi 5\% adalah sebesar 1,96 sehingga dinyatakan memiliki pengaruh yang signifikan. Pengujian masing-maisng hipotesis dibahas pada sub berikut:

Hasil pengujian hipotesis pertama menunjukkan bahwa pengaruh fashion involvement terhadap emosi positif menunjukkan nilai koefisien jalur sebesar 0,511 dengan nilai t-statistik sebesar 3,794. Nilai t-statistik lebih besar dari nilai ttabel 1,96 menunjukkan bahwa ada pengaruh signifikan antara variabel fashion involvement terhadap emosi positif. Koefisien jalurnya menunjukkan bahwa fash- 
ion involvement memberikan pengaruh positif terhadap emosi positif, artinya semakin tinggi fashion involvement, maka emosi positif juga akan semakin tinggi. Konsumen dengan fashion involvement yang tinggi cenderung merasakan emosi positif (senang, gembira, puas, bersemangat) saat berbelanja. Hasil penemun ini mendukung fashion involvement dapat meningkatkan pengalaman emosional konsumen saat berbelanja. Emosi positif saat berbelanja bisa menjadi faktor signifikan untuk mendorong impulsive buying. Hal ini berarti hipotesis 1 diterima.

Hasil pengujian hipotesis kedua menunjukkan bahwa pengaruh fashion involvement terhadap hedonisme menunjukkan nilai koefisien jalur sebesar 0,638 dengan nilai t-statistik sebesar 7,324. Nilai t-statistik tersebut lebih besar dari nilai t-tabel sebesar 1,96 yang menunjukkan bahwa ada pengaruh signifikan antara variabel fashion involvement terhadap hedonisme. Koefisiean jalurnya menunjukkan bahwa fashion involvement memberikan pengaruh positif terhadap hedonisme, artinya semakin tinggi fashion involvement maka hedonisme akan semakin tinggi. Konsumen yang suka berbelanja di fashion speciality store dan yang berpenampulan modis lebih mungkin menimbulkan hedonisme dalam berbelanja (memiliki dunia sendiri, menghilangkan stress, dll). Teori ini menyiaratkan bahwa pakaian sebagai produk indra eksperimental yang mempunyai peran penting hedonisme. Hal ini berarti hipotesis 2 diterima.

Hasil pengujian hipotesis ketiga menunjukkan bahwa pengaruh fashion involvement terhadap impulsive buying menunjukkan nilai koefisien jalur sebesar 0,277 dengan nilai t-statistik sebesar 2,087. Nilai t-statistik tersebut lebih besar 1,96 yang menunjukkan bahwa ada pegaruh signifikan terhadap variabel fashion involvement terhadap impulsive buying. Koefisien jalurnya menunjukkan bahwa fashion involvement memberikan pengaruh positif terhadap impulsive buying, artinya bahwa semakin tinggi fashion involvement maka impulsive buying akan semakin meningkat juga. Konsumen dengan fashion involvement yang tinggi lebih cenderung membeli model fashion terbaru dan berbelanja di fashion speciality store. Temuan ini mendukung fashion involvement mendorong impulsive buying konsumen Zara Bali. Hal ini berarti hipotesis 3 diterima.

Hasil pengujian hipotesis keempat menunjukkan bahwa pengaruh emosi positif terhadap impulsive buying menunjukkan nilai koefisien jalur sebesar 0,356 dengan nilai t-statistik sebesar 3,148. Nilai t-statistik tersebut lebih besar daripada nilai t-tabel 1,96 yang menunjukkan bahwa ada pengaruh signifikan antara variabel emosi positif terhadap impulsive buying. Koefisiean jalurnya menunjukkan bahwa emosi positif memberikan perngaruh positif terhadap impulsive buying, artinya semakin tinggi emosi positif maka impulsive buying juga semakin tinggi. Konsumen merasa lebih bersemangat, senang, gembira, dan puas saat mereka mengekspresikan berpetualang seperti memiliki dunia sendiri, ingin menghilangkan stress, mencoba hal baru. Temuan ini konsisten dengan penelitian sebelumnya yang menemukan perasaan positif dikaitkan dengan pengalaman belanja hedonisme (Hausman, 2000). Hal ini berarti hipotesis 4 diterima.

Hasil pengujian hipotesis kelima menunjukkan bahwa pengaruh hedonisme terhadap emosi positif menunjukkan nilai koefisien jalur sebesar 0,334 dengan nilai t-statistik sebesar 2,421. Nilai t-statistik tersebut lebih besar dari nilai t-tabel sebesar 1,96 yang menunjukkan adanya pengaruh signifikan antara variabel he- 
donisme terhadap emosi positif. Koefisien jalurnya menunjukkan bahwa hedonisme memberikan pengaruh positif terhadap emosi positif, artinya semakin tinggi hedonisme maka emosi positif juga akan semakin tinggi. Temuan ini mendukung hedonisme menyebebkan impulsive buying konsumen saat berbelanja. Hal ini berarti hipotesis 5 diterima.

Hasil pengujian hipotesis ke-enam menunjukkan bahwa pengaruh hedonisme terhadap impulsive buying menunjukkan nilai koefisien jalur sebesar 0,330 dengan nilai t-statistik sebesar 3,035. niali t-statistik tersebut lebih besar daripada nilai t-tabel yang menunjukkan bahwa ada pengaruh signifikan antara variabel hedonisme terhadap impulsive buying. Koefisien jalurnya menunjukkan bahwa hedonisme memberikan pengaruh positif terhadap impulsive buying, artinya semakin tinggi hedonisme makan impulsive buying akan semakin tinggi. Konsumen yang mempunyai perasaan senang, gembira, puas, dan bersemangat akan secara impulsif membeli produk fashion saat sedang berada di area toko. Hal ini mendukung emosi positif mengurangi kompleksitas keputusan dan menyebabkan impulsive buying. Hal ini berarti hipotesis 6 diterima.

\section{SIMPULAN}

Penelitian ini bertujuan untuk mengetahui faktor impulsive buying yang melatar belakangi emosi positif dan hedonisme dari pengaruh fashion involvement dengan menggunakan model yang dikembangkan oleh Park et al., (2006)sebagai berikut: 1). Fashion involvement memiliki pengaruh positif dan terhadap emosi positif. Konsumen lenih senang berbelanja di fashion speciality store dan memiliki pakaian dengan model terbaru dan menciptakan emosi positif. Semakin tinggi keterlibatan konsumen terhadap fashion maka semakin tinggi emosi positif yang dirasakan oleh konsumen; 2). Fashion involvement memiliki pengaruh positif dan signifikan terhadap hedonisme. Konsumen lebih senang belanja di fashion speciality store untuk meningkatkan hedonisme. Semakin tinggi keterlibatan konsumen terhadap fashion maka semakin tinggi sifat hedonisme yang dilakukan oleh konsumen; 3). Fashion involvement memiliki pengaruh positif dan signifikan langsung terhadap impulsive buying. Semakin tinggi keterlibatan konsumen terhadap fashion maka semakin tinggi tingkat pembelian impulsif yang dilakukan oleh konsumen, kususnya pada planned impulsive buying; 4). Hedonisme memiliki pengaruh positif signifikan terhadap emosi positif. Semakin tinggi hedonisme konsumen dalam berbelanja untuk menghilangkan stress, maka semakin tinggi emosi positif yang dirasakan oleh konsumen; 5). Hedonisme memiliki pengaruh positif signifikan terhadap impulsive buying. Semakin tinggi hedonisme konsumen dalam berbelanja maka semakin tinggi emosi positif yang dirasakan oleh konsumen; 6). Emosi positif memiliki pengaruh positif dan signifikan terhadap impulsive buying. Konsumen yang mempunyai perasaan senang, gembira, puas, dan bersemangat akan secara impulsif membeli produk fashion saat sedang berada di area toko. Semakin tinggi emosi positif konsumen dalam berbelanja maka semakin tinggi pembelian impulsif yang dilakukan konsumen.

Berdasarkan simpulan diatas saran yang dapat saya berikan sebagai berikut: 1). Pemilik toko diharapkan berkonsentrasi pada peningkatan edukasi lebih ten- 
tang fashion terhadap konsumen dengan memberikan katalog Zara, penggantian pakaian yang lebih sering pada mannequin, dan melatih staff nya untuk merekomendasi pakaian yang sedang trend kepada konsumen yang sedang berbelanja agar konsumen lebih aware tentang fashion; 2). Pemilik toko diharapkan menjaga atmosfir gerai Zara seperti seharusnya dengan memperhatikan kebersihan, kerapian, dan kenyamanan gerai agar pelanggan nyaman menghabiskan waktu untuk berlama-lama keliling toko hingga emosi positifnya menyababkan pembelian impulsive; 3). Peneliti disarankan untuk membangun model dan hasil dukungan menggunakan variabel lainnya seperti akeseibilitas waktu, keuangan, dan faktor social; 4). Penelitian ini dapat dilakukan juga untuk produk lain seperti kosmetik, aksesoris pribadi, model penelitian ini juga dapat diterapkan untuk populasi lainnya dan bisa diterapkan di wilayah geografis lainnya untuk meningkatkan generalisasi hasil

\section{REFERENSI}

Anjani, N. L. G. G. (2012). Pengaruh Fashion Involvement, Emosi Positif dan Hedonic Consumption Tendency terhadap Pembelian Impulsif di Department Store (Tesis). Yogyakarta: Universitas Atma Jaya Yogyakarta.

Arnold, M. J., \& Reynolds, K. E. (2003). Hedonic shopping motivations. Journal of Retailing, 79(2), 77-95.

Aryadini, R. F. (2012). Analisis Faktor - Faktor yang Mempengaruhi Perilaku Pembelian Impulsif pada Konsumen Produk Fashion di Jakarta (Skripsi). Yogyakarta: Universitas Indonesia.

Baron, R. A., \& Byrne, D. (2003). Social Psychology (10th ed.). New York: Pearson Education, Inc.

Beatty, S. E., \& Farrell, M. E. (1998). Impulse buying: Modeling its precursors. Journal of Retailing, 74(2), 169-191.

Brosekhan, A. A., \& Velayutham, C. . (2013). Consumer Buying Behaviour - A Literature Review. IOSR Journal of Business and Management (IOSR$J B M), 8-16$.

Cabanac, M. (1971). Physiological role of pleasure. Science, 173(4002), 11031107.

Dhurup, M. (2014). Impulsive Fashion Apparel Consumption: The Role of Hedonism, Fashion Involvement and Emotional Gratification in Fashion Apparel Impulsive Buying Behaviour in a Developing Country. Mediterranean Journal of Social Sciences, 5(8), 168-177.

Erlina, R. (2015). Pengaruh Gaya Hidup Berbelanja dan Keterlibatan Fashion 
terhadap Perilaku pembelian Impulsif Mahasiswa Srata 1 Manajemen Fakultas Ekonomi Universitas Jember (Skripsi). Jember: Universitas Jember.

Fukuyama, F. (2000). Social Capital and Civil Society. 1-18. International Monetary Fund.

Ghozali, I. (2008). Structural Equation Modeling Metode Alternatif dengan Partial Least Square. Semarang: Badan Penerbit Universitas Diponegoro

Hair, J. F., Ringle, C. ., \& Sarstedt, M. (2011). PLS-SEM: Indeed a Silver Bullet. Journal of Marketing Theory and Practice, 19(2), 139-152.

Han, Y. K., Morgan, G. A., Kotsiopulos, A., \& Kang-Park, J. (1991). Impulse buying behavior of apparel purchasers. Clothing \& Textiles Research Journal, 9(3), 15-21.

Hausman, A. (2000). A Multi-Method Investigation of Consumer Motivations in Impulse Buying. Journal of Consumer Marketing, 17(5), 403-426.

Hawkins, D. I., Best, R. J., \& Coney, K. . (1992). Consumer Behaviour: Implications For Marketing Strategy (5th ed.). Boston: Richard D Irwin Inc.

Herlambang S, N. (2008). Pengaruh Fashion Involvement, Emosi Positif dan Hedonic Consumption Tendency terhadap Impulse Buying di Matahari Department Store di Tunjungan Plaza Surabaya (Skripsi). Surabaya Petra Christian University.

Hermanto, E. Y. (2016). Pengaruh Fashion Involvement Terhadap Impulse Buying Behaviour Masyarakat Surabaya Dengan Hedonic Shopping Motivation Dan Positive Emotion Sebagai Variabel Intervening Pada Merek Zara. Jurnal Manajemen Pemasaran, 10(1), 11-19.

Hirschman, E. C., \& Holbrook, M. . (1982). The experiential aspects of consumption: consumer fantasies, feelings, and fun. Journal of Consumer Research, 9(2), 132-140.

Holmberg, J., \& Ohnfeldt, R. (2010). The female fashion consumer behaviourFrom the perspective of the shop Fever in Gothenburg (Thesis). Gothenburg: University of Gothenburg.

Ismayuni, I., \& Saraswati, T. G. (2015). Pengaruh Emosi Positif,Keterlibatan pada fashion dan Kecenderungan Konsumsi Secara Hedonis Terhadap Perilaku Pembelian Impulsif pada Konsumen Brand Fashion Nike. (Studi Pada Pengunjung Nike Store Bandung) (Skripsi. Bandung: Universitas 
Telkom.

Kotler, P., \& Amstrong, G. (2012). Principles of Marketing (14th ed.). New Jersey: Prentice Hall.

Laros, F. J. M., \& Steenkamp, J.-B. E. . (2005). Emotions in consumer behavior: a hierarchical approach. Journal of Business Research, 58(10), 1437-1445.

O'Brien, K. L., \& Leichenko, R. M. (2000). Double exposure: assessing the impacts of climate change within the context of economic globalization. Global Environmental Change, 10(3), 221-232.

O'Cass, A. (2000). An Assessment of Consumer Product, Purchase Decision, Advertising and Consumption Involvement in Fashion Clothing. Journal of Economic Psychology, 21(5), 545-576.

O'Cass, A. (2004). Fashion Clothing Consumption: Antecendents and Consequences of Fashion Clothing Involvement. European Journal of Marketing, 38(7), 869-882.

Park, E. J., Kim, E. Y., \& Forney, J. . (2006). A Structural Model of Fashion Oriented Impulse Buying Behavior. Journal of Fashion Marketing and Management, 10(4), 433-446.

Peter, J. P., \& Olson, J. C. (2005). Consumer Behavior \& Maketing Strategy (7th ed.). Boston: McGraw-Hill Book Company.

Piron, F. (1993). A Comparison of Emotional Reactions Experienced by Planned, Unplanned, and Impulse Purchasers. Advances in Consumer Research, 20, 341-344.

Putra, B. P., \& Mudiantono. (2014). Analisis Pengaruh Promosi, Emosi Positif dan Store Environment terhadap Perilaku Impulse Buying. Diponogoro Journal of Management, 3(4), 1-11.

Rohman, F. (2009). Peran Nilai Hedonik Konsumsi dan Reaksi Impulsif sebagai Mediasi Pengaruh Faktor Situasional terhadap Keputusan Pembelian Impulsif di Butik Kota Malang. JAM: Jurnal Aplikasi Manajemen, 7(2), 251-261.

Rook, D. W., \& Fisher, R. J. (1995). Normative Influence on Impulsive Buying Behavior. Journal of Consumer Research, 22(3), 305-313.

Rook, D. W., \& Gardner, M. . (1993). In the mood: impulse buying affective antecedents. Research in Consumer Behavior, 6(7), 1-28. 
Celina Andika Mulia, Fashion Involvement Mempengaruhi...

Scarpi, D. (2006). Fashion Store between Fun and Usefulness. Journal of Fashion Marketing and Management, 10(1), 7-24.

Sugiyono. (2012). Metode Penelitian Kuantitatif Kualitatif dan R\&D. Bandung: Alfabeta.

Tjiptono, F. (2002). Strategi Pemasaran. Yogyakarta: Andi Offset.

Zakiar, E. (2010). Faktor-Faktor Pendorong Konsumen Melakukan Impulsive Buying pada Toko-Toko Ritel Fashion di Jakarta (Tesis). Yogyakarta: Universitas Indonesia. 